\title{
Otomotiv Sektöründe Çalışan Kadın İşçilerin Ergonomik Risk Değerlendirmesi
}

\section{Ergonomic Risk Assessment of Female Workers Working in the Automotive Industry}

\author{
Seher Arslankaya $^{1}$ iD, Miraç Tuba Çelik ${ }^{1}$ iD

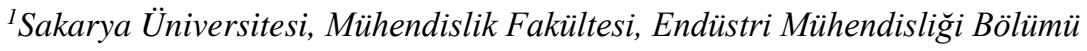

Başvuru/Received: 01/10/2021Ｋabul/Accepted: 30/12/2021Ｃ̧evrimiçi Basım/Published Online:31/12/2021

Son Versiyon/Final Version: 31/12/2021

\section{$\ddot{O} \mathbf{z}$}

Günümüzde otomotiv sektörünün giderek gelişmesi ile ülkemizde kadın işçiler işgücünün yaklaşık olarak \%30'dan fazlasını oluşturmaktadır. Kadın çalışanların sayısının giderek artması onların iş hayatlarında karşılaştıkları mesleki riskleri de beraberinde getirmektedir. Kadınların bedensel çalışma gücünün erkeklere oranla daha az olması nedeniyle çalışma hayatları boyunca fiziksel, kimyasal, ergonomik, biyolojik ve psiko-sosyal risklere maruz kalmaları sonucu ciddi sağlık problemleri yaşamaktadırlar. Bu nedenle meydana gelecek tüm sağlık sorunlarının önüne geçilebilmesi için ergonomik risklerin belirlenmesi ve değerlendirilmesi gerekmektedir. Bu çalışmada, bir otomotiv firmasında çalışan kadın işçilere ait son 4 yılda meydan gelen iş kazaları ele alınarak ergonomik risk değerlendirilmesi yapılmıştır. Ele alınan verilerle iş sağlığı ve güvenliği performansını gösteren değerler hesaplanmış ve kazaya neden olan risk faktörleri kendi aralarında sınıflandırılmıştır. Bu sınıflandırmanın ardından ergonomik risk faktörlerinden kaynaklı kazaların sayıları belirlenmiş ve öneriler sunulmuştur. Literatürde kadın çalışanlarına yönelik çalışmaların yetersiz olması sebebiyle bu çalışma yapılmıştır.

\section{Anahtar Kelimeler}

"Otomotiv, kadın çallş̧anlar, ergonomik risk, risk faktörleri"

\begin{abstract}
Today, with the gradual development of the automotive industry, female workers constitute more than $30 \%$ of the workforce in our country..The increasing number of female employees brings along the occupational risks they face in their business life.Due to the fact that women have less physical working power than men, they experience serious health problems as a result of their exposure to physical, chemical, ergonomic, biological and psycho-social risks throughout their working life.For this reason, ergonomic risks should be determined and evaluated in order to prevent all health problems that may occur.In this study, ergonomic risk assessment was made by considering the occupational accidents that occurred in the last 4 years of female workers working in an automotive company.Values showing occupational health and safety performance were calculated with the data discussed, and the risk factors causing the accident were classified among themselves.After this classification, the number of accidents caused by ergonomic risk factors was determined and suggestions were presented.This study was carried out due to the inadequacy of studies on female employees in the literature.
\end{abstract}

\section{Key Words}

"Automotive, female employees, ergonomic risk, risk factors" 


\section{Giriş}

Endüstri'nin gelişmeye başlamasıyla kadınların işgücüne katılma oranı tüm dünyada hızlı bir artış göstermektedir. Dünyada işgücünün yaklaşık \%30'dan fazlasııı kadın çalışanlar oluşturmaktadır (Çağlayan \& Karaca, 2015). Bu orana bakıldığında kadınların her türlü işkolunda çalıştığı görülmektedir. Bu da kadınların çalıştıkları yerlerde mesleki risklerle karşı karşıya kalma riskini aynı oranda arttırmaktadır (Yamankaradeniz vd., 2015). Bu risklerin ortaya çıkmasındaki sebeplerden biri kadınların sahip olduğu biyolojik, fizyolojik, sosyolojik ve psikolojik yapılarıdır (Aytaç vd., 2018). Kadın çalışanların erkek çalışanlara kıyasla daha küçük yapıda olmaları, daha az güçlü olmaları ve kas gücü gibi nedenlerle kadınların çalışma gücü erkeklerin çalışma gücünün yalnızca \%70-75'ine ulaşabilmektedir (Yılmaz, 2010). Aynı yaşta olan kadın ve erkek çalışanlar kıyaslandığında kadınların itme-çekme gücü erkeğe göre \%75 civarındadır. Kadınların omurga uzunluklarının erkeklerden daha fazla olması sebebiyle ağır yüklerin taşınması, yavaş olmayan iş temposu gibi durumlar kadınların ileride bel fitığı gibi kas-iskelet sistemi hastalıklarına daha çabuk yakalanacaklarını göstermektedir (Bilir \& Yıldız, 2014; Jafry, 2000).

Erkeklere göre kadınların 1sı toleransı ve vücut sıvıları daha az olduğundan sıcak ortamlardan daha fazla etkilenirler. Bu durum gebe çalışanlarda baş dönmesi ve baygınlık gibi birçok soruna neden olmaktadır (Çağlayan \& Etiler, 2009). Tüm bu durumlar incelendiğinde ergonomide önemli olan işin iş̧̧iye uydurulması ilkesi kadınların biyolojik, fizyolojik, sosyolojik ve psikolojik yapıları göz önüne alınarak her türlü sektörde önem kazanmalıdır (Çağlayan \& Karaca, 2015). Otomotiv sektörü bu sektörlerden bir tanesidir. Erkek çalışanların fazla olduğu bu sektörde kadın çalışanların sayısı da göz ardı edilemeyecek kadar fazladır. Gürültü, kimyasal, titreşim, ağır kaldırma, tekrarlı hareketler vb. birçok faktör otomotiv sektöründe çalışan kadınlar açısından büyük riskler oluşturmaktadır.

Her işletmede karşılaşılan riskler farklı olsa da 6331 sayılı iş sağlığı güvenliği kanunu işletmelerde karşılaşılan riskleri 5 başlık altında toplamıştır (Akalp \& Özok, 2017). Fiziksel riskler; gürültü, aydınlatma, sıcaklık ve nem, radyasyon, basınç, titreşim ve termal konfor şeklinde ele alınmaktadır (Efe \& Efe, 2015). Bu risk faktörleri kişilerin performanslarını, odaklanmalarını ve iş yapma kapasitelerini etkilemektedir (Akalp \& Özok, 2017). Kimyasallar sahip olduğu patlayıcı, zehirleyici, tahriş edici vb. özelliklerinden dolayı vücuda deri, solunum, gözler ve sindirim yolu ile girerek kişi üzerinde ciddi hasarlar bırakır. Bunlar kimyasal risk faktörleri olarak değerlendirilir (Efe \& Efe, 2015). Çeşitli nedenlerden dolayı çalışma ortamında bulunan mantarların, bakterilerin, parazitlerin, virüslerin çalışanlarda hastalığa neden olduğu riskler biyolojik risk faktörü olarak nitelendirilir. Stres, fazla iş yükü, mesai, mobing gibi çalışanın psikolojisini etkileyen riskler psiko-sosyal risk faktörleri olarak adlandırılır (Leka \& Cox, 2008). Çalışanların kas-iskelet sistemi hastalıklarına yakalanmalarına neden olan faktörlere ergonomik risk faktörleri denir (Kahraman, 2012). Çalışanların verimliliğini en fazla etkileyen faktörler ergonomik risk faktörleridir. Aydınlatma, titreşim, hava koşulları, sıcaklık gibi faktörler çalışanlar açısından büyük önem arz etmektedir (Stallworth \& Brain, 1996; Resnick \& Zanotti, 1997; Yapıcı \& Baş, 2015). Ergonomik risk faktörlerinin detaylı bir şekilde gösterimi Şekil 1'de gösterilmiştir (Aksüt \& Ark., 2020).

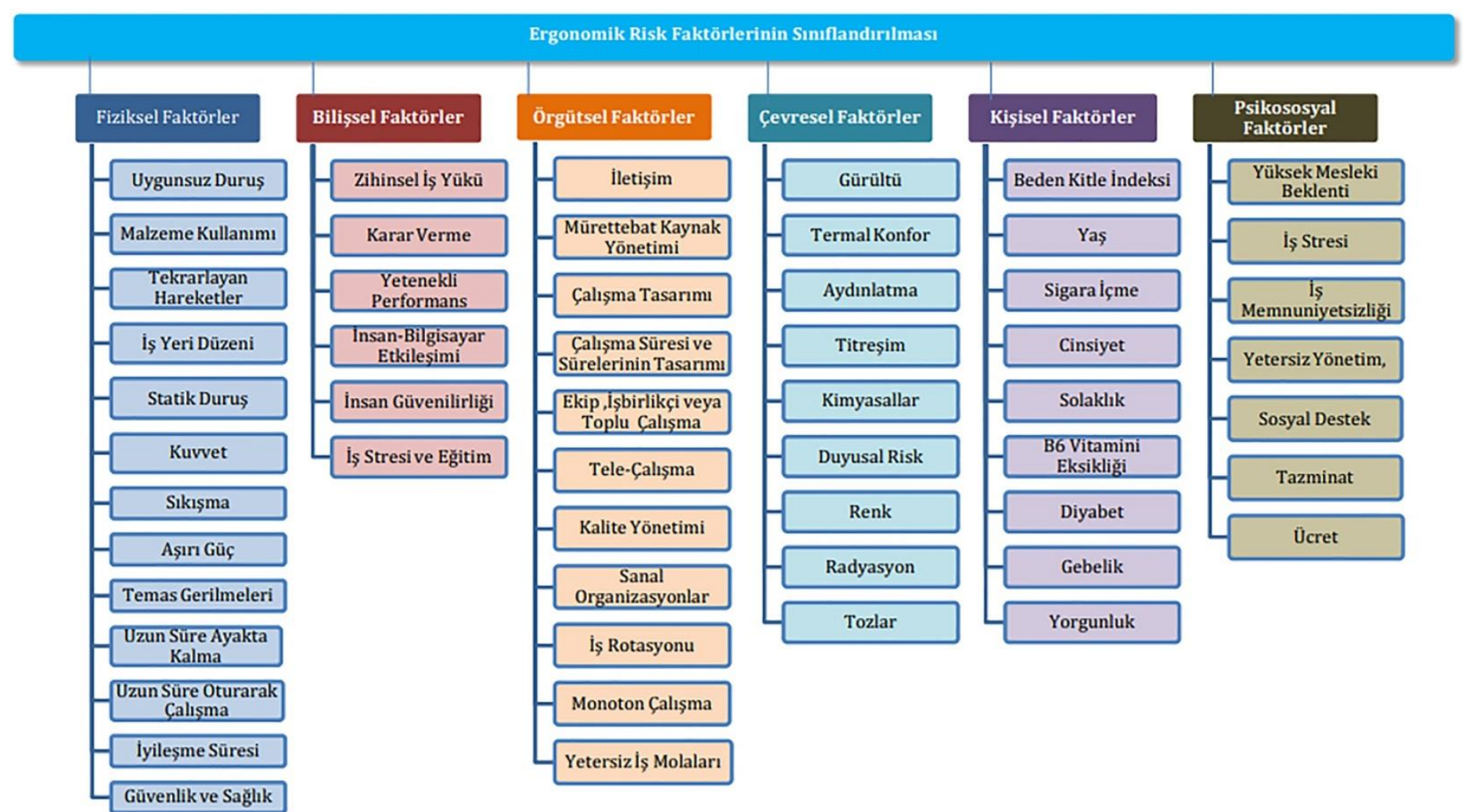

Şekil 1. Ergonomik Risk Faktörlerinin Sınıflandırılması 
Ergonomik risk faktörlerinin dikkate alınmadığı işletmelerde çalışanlarda meydana gelecek olan dikkat dağınıklığı, düşük verimlilik ve yorgunluk gibi birçok etken iş kazalarının artmasına neden olacaktır (Çağlayan \& Etiler, 2009). Ülkemizde 2019 yllında meydana gelen iş kazalarına baktığımızda kazaların \%79,9'una erkekler, \%20,1'ine kadınlar maruz kalmıştır.

Kadınları erkeklerden ayıran birçok faktörün olması nedeniyle işyerlerinde kadınlar erkeklerden daha yüksek risk taşımaktadır. Bu yüksek risk kadın çalışanların işletmelerde meydana gelecek kazalara ve birçok tehlikeye karşı özel olarak korunmasını gerektirmektedir. Sadece ülkemizde değil tüm dünyada kadınları koruyan çok sayıda düzenleme yapılmış olsa da hala bu düzenlemelerin yeterli seviyeye ulaşmadığı söylenebilir (Aytaç vd., 2018). İşletmelerde kadınların sağlığını etkileyen ergonomik riskler şu şekilde sıralanmıştır (Messing, 1998):

1. Kadınlara verilen işlerin sıradan, tekrarlı, statik güç gerektiren, fiziksel ve akıl sağlığı üzerinde zararlı etkisi olan işler olması,

2. Kadınları düşünmeden sadece erkek özellikleri dikkate alınarak hazırlanan alan, donanım gibi birçok etkenin kadınlar için uyun olmamas1,

3. Cinsiyete dayanan iş bölümlerinin yapılması sonucu kadınların işçi sağlığı ve güvenliği hizmetlerinden daha az yararlanması,

4. Yapılan ayrımcilıkların kadınlar üzerinde strese neden olması,

5. Kadınların yarı zamanlı çalıştığı işlerde sosyal haklardan yeteri şekilde yararlanamamaları,

6. Kadınlara ve erkeklere verilen görevlerin parçalanması sonucu tekrarlı çalışmanın ortaya çıkarak sağlığı etkilemesi.

Bu çalışmada Bursa'da faaliyet gösteren bir otomotiv firmasında çalışan kadın işçilere ait son 4 yılda meydana gelen iş kazaları ele alınarak ergonomik risk değerlendirilmesi yapılmıştır. Kaza sıklık hızı, kaza ağırlık oranı hesaplanmış ve kazalara neden olan risk faktörlerinin sınıflandırılması yapılmıştır. Ergonomik risk faktörlerinden kaynaklanan iş kazalarının sayısı ayrıca ele alınmıştır. Çalışmanın geri kalan kısmı şu bölümlerden oluşmaktadır: ikinci bölümde literatür taraması yapılmış, üçüncü bölümde materyal ve metot anlatılmış, dördüncü bölümde uygulama yapılmış ve beşinci bölümde sonuç bölümü oluşturulmuştur.

\section{Literatür Araştırması}

Ergonomik risklerin değerlendirilmesi ile ilgili literatürde çok sayıda çalışma yapılmıştır.

Pascual ve Naqvi (2008) kas-iskelet sistemi hastalıklarına neden olan ergonomik risklerin değerlendirilmesinde kullanılan yöntemleri incelemiştir. Yaptıkları çalışmada ergonomik risk değerlendirmesinde çalışanların öz bildirimlerini kullandıklarını görmüşlerdir.

David (2005) çalışan kişilere sorulan sorulardan gelecek cevapların ergonomik risk faktörlerinin analiz edilmesinde kullanılacak yöntemlerden birisi olduğunu söylemiştir.

Taşoluk (2011) hazır giyim işletmesinde çalışan kişilerin uğradığı iş kazalarını, meslek hastalıklarını ve yorgunluğa neden olan risk faktörlerini belirleyerek iyileştirmelerde bulunmuştur.

Chiasson vd., (2015) kas-iskelet ağrısı olan ve olmayan işçilerin ergonomik risk faktör değerlendirmesini yapmışlardır.

Efe ve Efe (2015) tekstil sektöründe meydana gelen iş kazalarına ait ergonomik riskleri değerlendirmiş ve iyileştirme önerilerinde bulunmuşlardır.

Veselinovic vd., (2016) bilgisayar tabanlı bir uzman sistem(SONEX) geliştirerek kas-iskelet sistemi hastalıkları için ergonomik riskleri belirlemişlerdir.

Felekoğlu ve Taşan (2017) reaktif ve proaktif bakış açılarını kapsayan ergonomik risk değerlendirme yaklaşımı geliştirerek metal sektöründe faaliyet gösteren bir firmada uygulama yapmışlardır.

Yürek ve Kaya (2019) yol inşaatı şantiyelerinde çalışan kişilerin ergonomik risk değerlendirilmelerini yapmışlardır.

Kahya ve Çiçek (2019) seramik fabrikasında 3 ünitede REBA ve BAU yöntemleri kullanarak ergonomik risk değerlendirmesi yapmışlardır. Çalışma sonucunda iyileştirme önerilerinde bulunulmuş ve REBA skoru 42'den 13'e düşürülmüştür.

Rathore vd., (2020) cam sanatı işçileri arasında yaygın olan kas-iskelet sistemi hastalıklarına neden olan ergonomik risk faktörlerini araştırmışlardır.

Bozkurt vd., (2020) Van'da faaliyet gösteren otel işletmelerindeki ergonomik riskleri belirlemişlerdir. Çalışma 4 ve 5 yıldızlı otelleri kapsamaktadır. Çalışma sonucunda otel işletmelerinde birkaç eksiğin olduğunu ancak kullanılan malzemelerin ergonomik açıdan uygun olduğunu belirlemişlerdir.

Aksüt vd., (2020) ergonomik risk faktörleri ve sınıflandırılması ile ilgili bir literatür taraması yapmışlar ve sektörler bazında karşılaşılan risk faktörlerini belirlemişlerdir.

Literatüre bakıldığında kadın işçilere yönelik çok az sayıda çalışma yapıldığı görülmektedir. 
Wamalaa vd. (2000) yaptıkları çalışmada kadın işçilerin yaşadıkları iş stresinin koroner kalp yetmezliği problemini dört kat arttığını söylemiştir.

Björksten vd., (2001) metal ve gıda sektöründe çalışan 173 kadın işçinin kas-iskelet sistemi problemini araştırmış ve kadın çalışanlarda omuz ve boyun probleminin çok ciddi olduğunu belirtmişlerdir.

Dahlberg vd., (2004) yaptıkları çalışmada erkek ve kadın çalışanların performanslarını, çalışma tekniklerini ve kas-iskelet sistemi sorunları arasındaki farklılıkları incelemişlerdir. Çalışma sonucunda kadınların el becerisi gerektiren işlerde erkeklere oranla daha fazla çalıştı̆̆ ve omuz zedelenmelerine yakalanma oranının kadınlarda daha fazla olduğunu belirtmişlerdir.

Yamankaradeniz vd., (2015) yaptıkları çalışmada kadın işçilerin maruz kaldıkları fiziksel risk algısını ölçmüş ve risk alanlarındaki güvenlik farkındalıklarını tespit etmişlerdir. Toplam 582 kadın işçiden alınan anket verilerine göre en önemli faktörün iş sağlığı ve güvenliği eğitimleri olduğu anlaşılmıştır.

Borah (2015), Hindistan'daki kaju fıstığı işleme fabrikasında çalışan kadın işçilerin ergonomik değerlendirilmesini yapmışlardır.

Aytaç vd., (2018) metal sanayide çalışan 23 iş yerindeki toplam 1918 kadın işçiye yaptıkları anket ile ergonomik risk algısı, kadercilik algısı ve güvenli davranış farkındalığını ölçmüşlerdir. Yapılan çalışma sonucunda ergonomik risk faktörü bakımından kadın işçilerde ilk olarak kas-iskelet sistemi sorunlarına yönelik bulgular olduğu tespit edilmiştir.

\section{Materyal ve Metot}

Kaza sıklık oranı ve kaza ağırlık oranı bir işletmenin iş sağlığı ve güvenliği performansını gösteren değerler arasında yer almaktadır.

İş kazası sıklık hızı veya oranı, belirli bir zaman süresi içinde yaşanan ve bir günden fazla iş göremezliğe sebep olan kaza sayısını ifade eder. Kaza sıklık oranı iki şekilde hesaplanabilir. İlk yöntem 1 milyon çalışma saati başına yaşanan kaza sayısını ifade eder (Efe \& Efe, 2015). Bu yöntemde ele alınan dönemde toplam meydana gelen iş kazası sayısı ve toplam kaç saat çalışıldığının bilinmesi gerekir. Toplam çalışılan saat hesaplanırken çalışılan gün sayısından çalışılmayan gün sayılarının çıkarılması gerekir.

Kaza Sıklık Hızı $=\frac{\text { Kaza sayısı }}{(\text { Toplam çalışma günü }- \text { çalışllmayan gün sayısı }) \times \text { günlükçalışma süresi }} \times 1.000 .000$

Toplam çalışma günü = Dönem içindeki gün sayısı × çalışan sayısı

Örneğin, 200 işçinin çalıştığı bir işletmede 50 günde 10 iş kazası olduysa,

Kaza sıklık hızı $=\frac{10}{200 \times 50 \times 8} \times 1.000 .000=125$ olarak hesaplanır.

Eğer 100 işçi için 50 hafta boyunca haftada 45 saat çalışıldığında meydana gelecek iş kazasını bulmak için 100 işçinin kaç saat çalışı̆̆ı̆ının hesabının yapılması gerekir. Yani yıllık tahmini 1.000 .000 çalışma saati değişmiş olacaktır. Bu durumda 100 işçi, 50 haftada ve haftada toplam 45 saat çalışırsa 225.000 iş saati/yıl çalışmış olacaktır. O nedenle ilk yöntem ile değil de ikinci yöntem ile hesap yapmak gerekir (Simonds \& Grimaldi, 1983). Yani burada tam gün çalışan her 100 kişi arasında meydana gelen kaza sayısı hesaplanmaktadır (Efe \& Efe, 2015).

Kaza Sıklık Hızı $=\frac{\text { Kaza sayısı }}{(\text { Toplam çalışma günü }- \text { çalışslmayan gün sayısı }) \times \text { günlükkçalışma süresi }} \times 225.000$

Toplam çalışma günü = Dönem içindeki gün sayısı × çalışan sayısı

Kaza ağırlık oranı, belirli bir zaman süresi içinde iş kazaları nedeniyle oluşan toplam kayıp gün sayısıdır. Bu oran iki şekilde hesaplanabilmektedir. İlk yöntem 1.00 .0000 çalışma saatinde kaç iş gününün kaybedildiğini göstermektedir (Efe \& Efe, 2015). Bu yöntemde ele alınan dönemde toplam gün kaybı ve toplam kaç saat çalışıldığının bilinmesi gerekir.

Kaza ağırlık oranı $=\frac{\text { Toplam gün kaybı }}{(\text { Toplam çalışma günü }- \text { çalışllmayan gün sayısı }) \times \text { günlükç̧alışma süresi }} \times 1.000 .000$

Toplam çalışma günü = Dönem içindeki gün sayısı × çalışan sayısı

Örneğin, 200 işçinin çalıştı̆̆ bir işletmede 50 iş gününde 7 iş günü kaybı olduysa (Simonds \& Grimaldi, 1983), 
Kaza ağırlık oranı $=\frac{7}{200 \times 50 \times 8} \times 1.000 .000=87,5$ olarak hesaplanır.

Her 100 saatte kaç iş gününün kaybedildiğini bulmak için ikinci yöntem kullanılır (Efe \& Efe, 2015).

Kaza ağırlık oranı $=\frac{\text { Toplam gün kaybı }}{(\text { Toplam çalışma günü-çalış̧lmayan gün sayısl }) \times \text { günlükçalışma süresi }} \times 100$

\section{Uygulama}

Bu çalışma Bursa'da faaliyet gösteren bir otomotiv firmasında yapılmıştır. Firmada çalışan kadın işçilerin son 4 yılda uğradığı iş kazaları dikkate alınmış ve ergonomik risk değerlendirmesi yapılmıştır. Firmada ele alınan veriler sayesinde kaza sıklık oranı ve kaza ağırlık oranı hesaplanmıştır. Bu verilerin iş sağlığı ve güvenliği performansını gösteren veriler olmasından dolayı bu çalışmada kullanılmasına karar verilmiştir. Firmada meydana gelen kazalar fiziksel, kimyasal, biyolojik, psiko-sosyal ve ergonomik risk faktörleri bakımından sınıflandırılmıştır. Sınıflandırmanın ardından ergonomik risk faktörlerinden kaynaklanan iş kazaları da ergonomik temeline göre incelenerek tablo halinde sınıflandırılmıştır.

Kaza sıklık hızı ve kaza ağırlık oranının hesaplanabilmesi için 2017-2020 yılları arasında kadın işçilerde meydana gelen iş kazası sayısının ve kayıp gün sayısının bilinmesi gerekir. Şekil 2'de iş kazası sayıları ve şekil 3'de kayıp gün sayıları grafik yardımı ile gösterilmiştir.

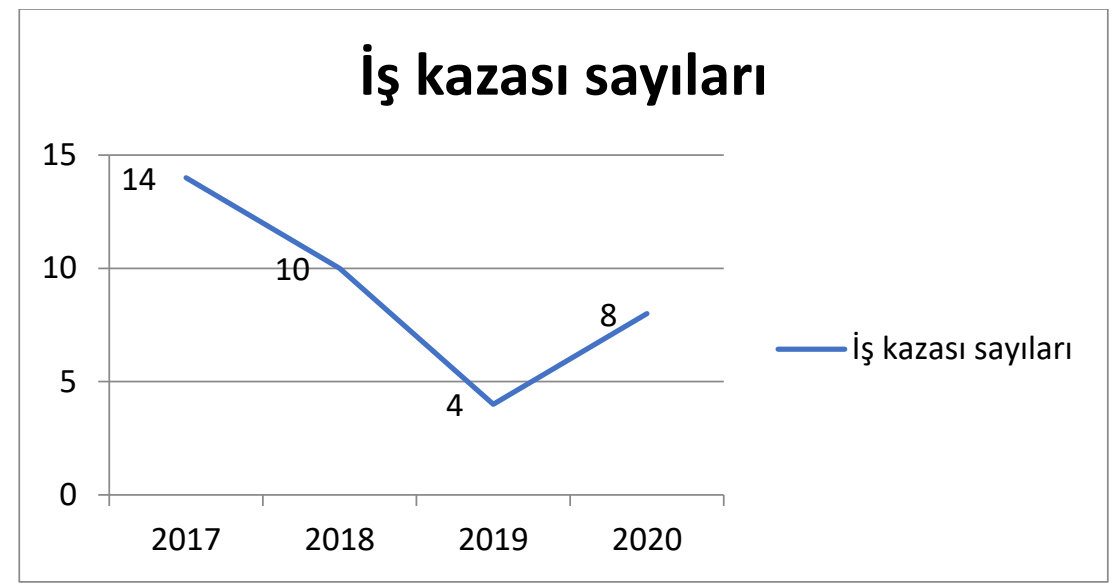

Şekil 2. 2017-2020 Yılları Arasında Kadın İşçilerde Meydana Gelen İş Kazası Sayıları

4 yıl içinde toplamda 36 iş kazası meydana gelmiştir. Şekil 1 incelendiğinde iş kazalarının en fazla 2017 yılında meydana geldiği görülmektedir. 2017 yılında gerekli iş sağlığı ve güvenliği önlemlerinin alınmadığı veya diğer yıllara oranla iş kazası kayıtlarının daha özenle tutulduğu düşünülmektedir. 2018 yılı meydan gelen kaza sayıları sıralamasında 2.sırada yer alırken, en az kaza 2019 yılında olmuştur. Covid-19 nedeniyle 2019 ve 2020 yıllarında firmaların daha az gün çalışması meydana gelen kaza sayılarını da etkilemiştir.

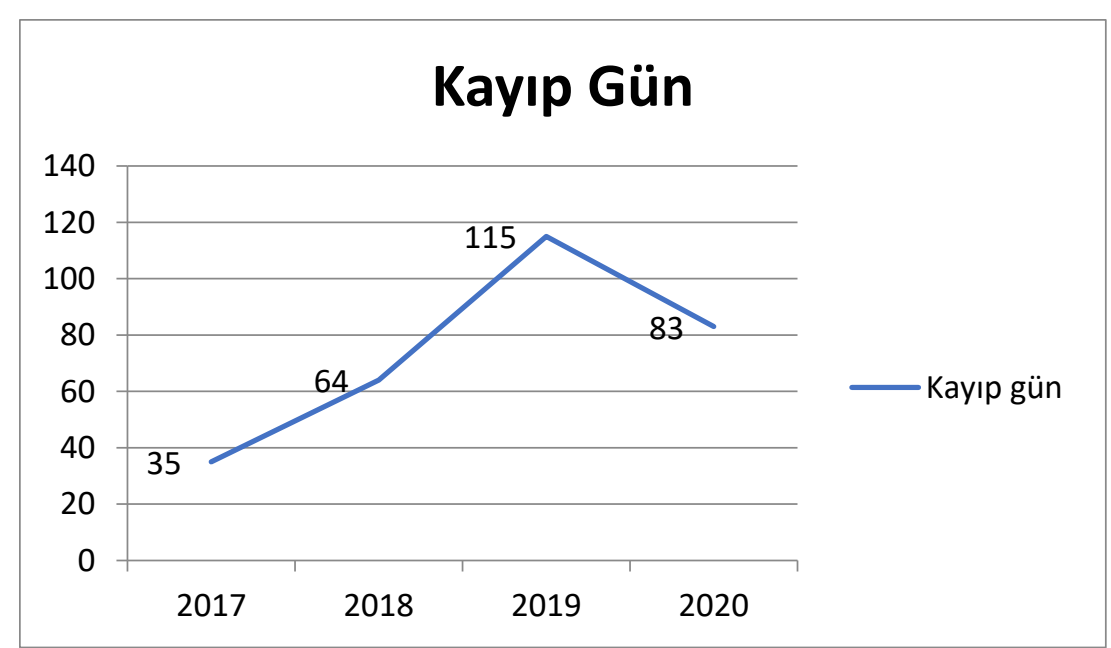

Şekil 3. 2017-2020 Yılları Arasında Kadın İşçilerde Meydana Gelen Kayıp Gün Sayıları

Şekil 3'deki grafiğe bakıldığında en fazla kayıp günün 2019 yılında, en az kayıp günün ise 2017 yılında olduğu görülmektedir. 
İşs sağlığı ve güvenliği performansını gösteren kaza sıklık hızı ve kaza ağırlık oranı değerleri tablo 1'de gösterilmiştir.

Tablo 1. 2017-2020 Yılları Arasındaki Kaza Sıklık Hızı ve Kaza Ağırlık Oranı

\begin{tabular}{ccc}
\hline Yıllar & Kaza Sıklık Hızı & Kaza Ă̆ırlık Oranı \\
\hline $\mathbf{2 0 1 7}$ & 14,69 & 0,0251 \\
$\mathbf{2 0 1 8}$ & 11,92 & 0,0458 \\
$\mathbf{2 0 1 9}$ & 6,08 & 0,1295 \\
$\mathbf{2 0 2 0}$ & 10,32 & 0,1014 \\
\hline
\end{tabular}

Firmada meydana gelen iş kazaları birçok risk faktöründen kaynaklanmaktadır. Bunlar; fiziksel, kimyasal, biyolojik, psiko-sosyal ve ergonomik risk faktörleridir. 2017-2020 yılları arasındaki toplam kaza sayıları tablo 2'de risk faktörlerine göre sınıflandırılmıştır.

Tablo 2. Risk Faktörleri

\begin{tabular}{cc}
\hline Risk Faktörleri & Değerler \\
\hline Fiziksel & 3 \\
Kimyasal & 5 \\
Biyolojik & - \\
Psikososyal & 8 \\
Ergonomik & 20 \\
\hline
\end{tabular}

Firmada en fazla kazaya sebep olan risk faktörü ergonomik risk faktörüdür. Kazaların, ağır kaldırma, tekrarlayan hareketler yapma, uzun süre çalışma vb. faktörden kaynaklanması ergonomik risk faktörünün 1.sırada yer almasına sebep olmuştur. 2.sırada ise psikosoyal risk faktörleri gelmektedir. Risk faktörlerinin yüzde olarak gösterimi şekil 4'de pasta grafiği yardımı ile gösterilmiştir.

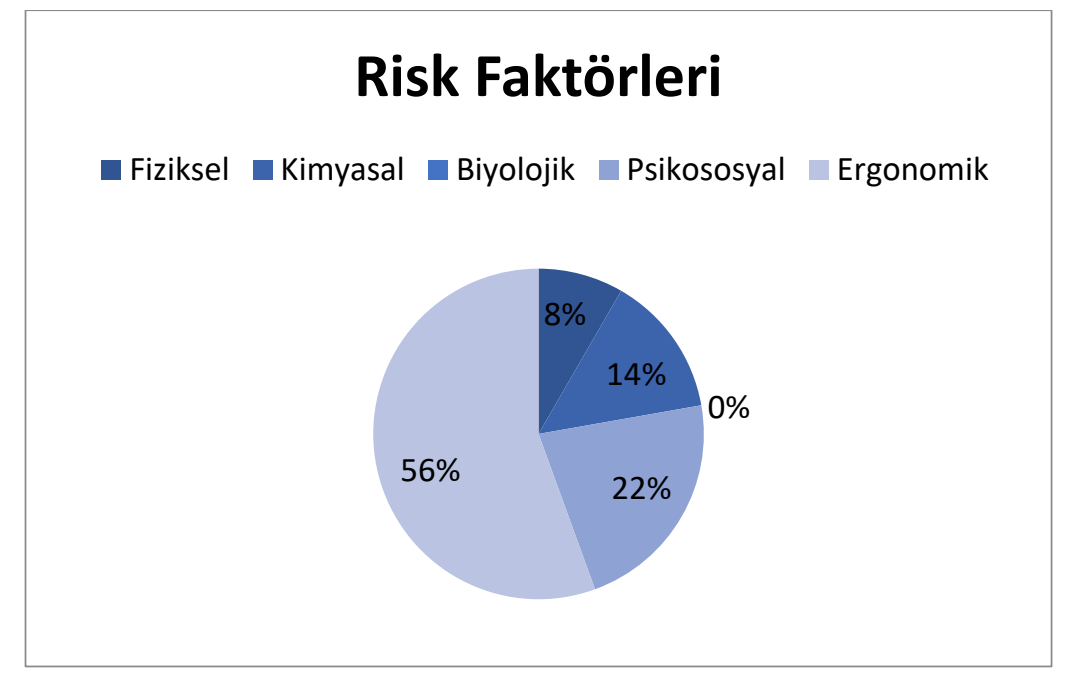

Şekil 4. Risk Faktörlerinin Yüzde Olarak Gösterimi

Firmada ergonomik risk faktörlerinden kaynaklı iş kazalarının sınıflandırılması tablo 3'de gösterilmiştir.

Tablo 3. Ergonomik Temelli Nedenler ve Kaza Sayıları

\begin{tabular}{ll}
\hline Ergonomik temelli nedenler & Kaza Sayısı \\
\hline Tekrarlayan hareketler & 4 \\
Ağır kaldırma & 5 \\
Malzeme kullanımı & 7 \\
İs yeri düzeni & 2 \\
Uygunsuz duruş & 2 \\
\hline
\end{tabular}

Firmadaki ergonomik temelli nedenlere bakıldığında en fazla malzeme kullanımı ve ağır kaldırmadan kaynaklandığı görülmektedir. İ̧̧ sırasında çalışanların kullandığı kesici alet ile ellerini kesmesi firmada en çok karşılaşılan kazalardandır. Üretilen ürünlerin ağır olmasından dolayı kadın çalışanların ürünleri kaldırırken veya taşırken düşmesi de çok sık rastlanan iş kazalarının başında gelmektedir. 


\section{Sonuç}

Geçmiş veriler incelendiğinde; günümüzde kadın çalışanların farklı sektörlerde istihdamının arttı̆̆ı görülmektedir. Bu sektörlerin başında otomotiv sektörü gelmektedir. Otomotiv sektöründe çalışan kadınların çeşitli iş tanımlarının olması birçok sorunu da beraberinde getirmektedir. Bu sorunun başında iş kazaları gelmektedir. İşletmelerde çeşitli etmenlerden kaynaklı kadın çalışanların erkek çalışanlardan daha yüksek risk taşıdığı değiştirilemez bir gerçektir. Bu etmenler; anatomik yapı, eğitim, tecrübe, antropolojik, psikolojik nedenler şeklinde sıralanabilir.

Bu çalışmada Bursa'da faaliyet gösteren bir otomotiv firmasında kadın işçilerin ergonomik risk değerlendirmesi yapılmıştır. İlk önce firmada çalışan iş sağlığı ve güvenliği uzmanından 2017-2020 yılları arasında kadın işçilerde meydan gelen iş kazası sayısı, kayıp gün sayısı ve kadın çalışan sayısı bilgileri alınmıştır. Ardından kaza sıklık hızı ve kaza ağırlık oranı hesaplanmıştır. Devamında kadın çalışanlarda meydana gelen iş kazalarının hangi risk faktörlerinden kaynaklandığı araştırılmış ve sayısal sonuçlar tablo halinde gösterilmiştir. Sonuçlar incelendiğinde en fazla ergonomik risk faktörlerinden kaynaklı iş kazalarının olduğu sonucuna ulaşılmıştır. Diğer risk faktörleri içinde \%56 lık bir paya sahip olduğu görülmüştür. Bu sonucun 5 farklı etmenden kaynaklandığı görülmüştür. Bu etmenlerin başında malzeme kullanımı gelmektedir. Firmada ergonomik olmayan çalışma araçlarının kullanılması işçilerde çeşitli yaralanmalara sebebiyet vermektedir. Ergonomik açıdan daha uygun bir çalışma aletinin firmaya alınması bu sorunu çözmeye yardımcı olabilir. Firmada çalışanların uygunsuz duruşlarından kaynaklı meydana gelen kazaların azaltılması için çalışanlara gerekli eğitimlerin verilmesi gerekmektedir. İş yerindeki düzenden kaynaklı çalışanlarda meydana yorgunluk, vücutta meydana gelen ağrılar, gürültüden kaynaklı işitme sorunlarının yaşanmasına neden olmaktadır. Bu sorunun giderilmesi için mühendisler tarafından iş yeri düzenin gözden geçirilmesi gerekmektedir. İşletmenin ergonomi çalışmalarına daha fazla önem vermesi ve iş kaza sayılarının en aza indirilmesi gerekmektedir.

Literatürde yapılan çalışmalara bakıldığında kadın çalışanlar ile ilgili yeterli çalışmaların olmadığı görülmüş ve bu çalışmanın yapılmasına karar verilmiştir.

\section{Referanslar}

Akalp, G., \& Özok, A.F. (2017). Ergonomik Risklerin Bulanık Mantık Yöntemi ile Modellenmesi ve Bir Uygulama. Mühendislik Bilimleri ve Tasarım Dergisi, 5, 69-79. doi.org/10.21923/jesd.19802

Aksüt, G., Eren, T., \& Tüfekçi, M. (2020). Ergonomik Risk Faktörlerinin Sınıflandırılması: Bir Literatür Taraması. Ergonomi, 3(3), 169-192. doi.org/10.33439/ergonomi.773896

Aytaç, S., Özok, A.F., Yamankaradeniz, N., Gökçe, A., Akalp, G., Çankaya, O., \& Tüfekçi, U. (2018). Metal Sanayinde Çalışan Kadınların Ergonomik Risk Algısı: Bir Araştırma, Ergonomi, 1(1), 29-38. doi.org/10.33439/ergonomi.473023

Bilir, N., \& Yıldız, A.N. (2014). İş Sağlığı ve Güvenliği, Ankara, Hacettepe Üniversitesi Yayınları.

Björkstén, M.G., Boquist, B., Talbäck, M., \& Edling, C. (2001). Reported Neck and Shoulder Problems in Female İndustrial Workers: The İmportance of Factors at Work and at Home. International Journal of Industrial Ergonomics, 27(3), 159-170. doi.org/10.1016/S0169-8141(00)00047-0

Borah, S. (2015). Ergonomic Assesment of Drudgery of Women Worker Involved in Cashew Nut Processing Factory in Meghalaya, India. Procedia Manufacturing, 3, 4665-4672. doi.org/10.1016/j.promfg.2015.07.557

Bozkurt, Ö., Meriç, S., \& Kaymış, B. (2020). Otel İşletmelerinde Bulunan Ergonomik Risklerin Değerlendirilmesi: Van Örneği. Journal of Tourism Theory and Research, 6(1), 20-34. doi.org/10.24288/jttr.613975

Chiasson, M.E., Imbeau, D., Major, J., Aubry, K.., \& Delisle, A. (2015). Influence of Musculoskeletal Pain on Workers Ergonomic Risk -Factor Assessments. Aplplied Ergonomics, 49, 1-7. doi: 10.1016/j.apergo.2014.12.011

Çağlayan, Ç., \& Etiler, N. (2009) Türkiye'de Kadın İşçilerin Meslek Sağlığı. Türk Tabipler Birliği Mesleki Sağlık Ve Güvenlik Dergisi, 9(33), 23-31.

Çağlayan, Ç., \& Karaca, E. (2015). Ergonomi ve Kadın İşçiler. Türk Tabipleri Birliği Mesleki Sağlık ve Güvenlik Dergisi, 15(57), $24-$ 28.

Dahlberg, R., Karlqvist, L., Bildt, C., \& Nykvist, K.. (2004). Do Work Technique and Musculoskeletal Symptoms Differ Between Men and Women Performing The Same Type of Work Tasks. Applied Ergonomics, 35(6), 521-529. doi: 10.1016/j.apergo.2004.06.008

David, G.C. (2005). Ergonomic Methods for Assessing Exposure to Risk Factors for Work-Related Musculoskeletal Disorders. Occupational Medicine, 55(3), 190-199. doi: 10.1093/occmed/kqi082 
Efe, Ö.M., \& Efe, B. (2015). Tekstil Sektöründe İş Kazalarının Oluşumuna Ait Ergonomik Risklerin Değerlendirilmesi. Süleyman Demirel Üniversitesi Mühendislik Bilimleri ve Tasarım Dergisi, 3(3), 623-629. doi:10.13140/RG.2.1.1268.8408

Felekoğlu, B., \& Taşan, S.Ö. (2017). İş İle İlgili Kas İskelet Sistemi Rahatsızlıklarına Yönelik Ergonomik Risk Değerlendirme: Reaktif/Proaktif Bütünleşik Bir Sistematik Yaklaşım. Mühendislik Mimarlık Fakültesi Dergisi Gazi üniversitesi, 32(3), 777-793. doi.org/10.17341/gazimmfd.337625

Jafry, T. (2000). Women, Human Capital and Livelihoods: An Ergonomics Perspective. Natural Resource Perspectives, 54, London. http://hdl.handle.net/10535/3665

Kahraman, M.F. (2012). Ergonomik Risk Değerlendirme Yöntemlerinin Çok Ölçütlü Karar Verme Teknikleri ile Önceliklendirilmesi ve Bütünleşik Bir Model Önerisi. Yüksek Lisans Tezi. Gazi Üniversitesi, Ankara.

Kahya, E., \& Çiçek, E. (2019). Seramik Sektöründe Taşıma İşlemlerinde Ergonomik Risk Değerlendirmesi-Bir Pilot Çalışma. Ergoterapi Ve Rehabilitasyon Dergisi, 7(1), 47-58. doi.org/10.30720/ered.419016

Leka, S., \& Cox, T. (2008). PRIMA-EF Guidance on the European Framework for Psychosocial Risk Management: A Resource for Employers and Worker Representatives, WHO Protecting Workers' Health Series, 9. ISBN 978924159710 4, ISSN 1729-3499.

Wallace R B. (1988). Maxcy-Rosenau-Last Public Health and Preventive Medicine. New York, Appleton \& Lange

Pascual S.A., \& Naqvi S. (2008). An İnvestigation of Ergonomics Analysis Tools Used in Industry in the İdentification of WorkRelated Musculoskeletal Disorders. International Journal of Occupational Safety and Ergonomics, 14(2), 237-245. doi: $10.1080 / 10803548.2008 .11076755$

Rathore, B., Pundir, A.K., \& Iqbal, R. (2020). Ergonomic Risk Factors in Glass Artware Industries and Prevalence of Musculoskeletal Disorder. International Journal of Industrial Ergonomics, 80, 103043. doi:10.1016/j.ergon.2020.103043

Resnick, M.L., \& Zanotti, A. ( 1997). Using Ergonomics to Target Productivity Improvements. Computers \& Industrial Enginering, 33(1-2), 185-188. doi.org/10.1016/S0360-8352(97)00070-3

Simonds, R.H., \& Grimaldi, J.V. (1956). Safety management : Accident Cost and Control. Homewood, Richard D. Irwin.

Stallworth, O.E., \& Kleiner, B.H. (1996). Recent Developments in Office Design, Facilities, 14(1/2), $34-42$. doi.org/10.1108/02632779610108512

Taşoluk, A. (2011). Hazır Giyim Üretiminde Meslek Hastalıkları, Yorgunluk ve İş Kazaları Risk Faktörlerinin Değerlendirilmesi: Örnek Uygulama. Yüksek Lisans Tezi. Selçuk Üniversitesi, Konya.

Veselinovic, S.P., Hedge, A., \& Veselinovic, M. (2016). An Ergonomic Expert System for Risk Assessment of Work-Related MusculoSkeletal Disorders. International journal of Industrial Ergonomics, 53, 130-139. doi.org/10.1016/j.ergon.2015.11.008

Wamalaa, S.P., Mittleman, M.A., Horsten, M., Gustafsson, K.S., \& Gomer, K.O. (2000). Job Stress and the Occupational Gradient in Coronary Heart Disease Risk in Women. Social Science \& Medicine, 51(4), 481-489. doi: 10.1016/s0277-9536(00)00006-x

Yamankaradeniz, N., Akalp, G., \& Çankaya, O. (2015). Otomotiv Ve Metal Sektöründe Çalışan Kadınların Maruz Kaldıkları Fiziksel Risk Algısı. Süleyman Demirel Üniversitesi Mühendislik Bilimleri ve Tasarım Dergisi, 3(3), 449-458. Doi:10.21923/MBTD.25100

Yapıcı, F., \& Baş, H. (2015). Verimlilikte Ergonomik Faktörler. Süleyman Demirel Üniversitesi Mühendislik Bilimleri ve Tasarım Dergisi, 3(3), 591-595.

Yılmaz F. (2010). Türkiye'de Kadın Çalışanların Mesleki Sağlık ve Güvenlik Koşulları. Uluslararası Sosyal Araştırmalar Dergisi, 3(13), 268-284.

Yürek, K., \& Kaya, İ.E. (2019). Yol İnşaatı Şantiyelerinde Ergonomik Risk Değerlendirmesi, Avrupa Bilim Ve Teknoloji Dergisi, sayı 17, 1357-1366. doi.org/10.31590/ejosat.667469 